\begin{tabular}{|c|c|}
\hline \multirow{3}{*}{ 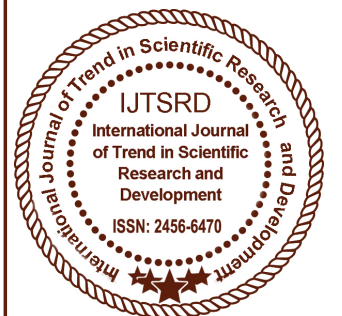 } & $\begin{array}{l}\text { International Journal of Trend in Scientific } \\
\text { Research and Development (IJTSRD) }\end{array}$ \\
\hline & International Open Access Journal \\
\hline & ISSN No: 2456 - 6470 | www.ijtsrd.com | Volume - 2 | Issue - 5 \\
\hline
\end{tabular}

\title{
Research on the Talent-Athletes and Effective Management Training for Complete Competition
}

\author{
Kyaw Naing Soe \\ Assistant Director, Department of Sports and Physical Education Ministry of \\ Health and Sports, Myanmar
}

\begin{abstract}
Talent athlete is a vital component of many sport activities. There are various terms in the field of Talent athlete such as Talent Detection, Talent Screening, Talent Development, Talent Selection. Which is clearly before selection Talent athletes .Long-Term athlete development based on the 7-Key element have including Active Start, Fundamental, Learning to train, Training to train, Training to Compete, Training to Win and Active for Life.
\end{abstract}

Keyword: Talent Screening, Talent Detection, Talent Development, Talent Selection.

\section{INTRODUCTION}

Sport sector can raise National prestige through its National development and achievement and effectively and beneficially and not only the Government but also sport loving people from private enterprises and organizations are supporting for the development of sports, has been in process of reinvention, taking into consideration the need for a strategic re-evaluation of the multi-cultural and multidimensional components of sport. In today's sport, all the sport loving people of the national, Regional must contribute to the fostering social, economic, cultural if we are to successfully develop a platform to turn our athlete into the Elite - athlete's heroes. Sport training is a Fundamental for achievement of progress in sport training standard will be win and loser. Sport training will be able to occur morphological, physiological, biochemical and psychological change .It depend on the sport volume and sport intensity, sport Frequency and sport density of workout and this factor of training depend on the period of training and the individual athlete needs. If we want to need achievement, Fundamental Rule of sport Training as follow, Training Ability is the very important to improve in response to training and it depend on the training age and Fitness of the individual athletes. Recovery Ability is to achievement of sport competition, it's depending on the time of the rest. Adaptation form rapidly with high-intensity work, do not last. They must form very slowly with a little bit High volume.

\section{HIGH- PERFORMANCE ATHLETES}

In all sport, physical training can only take you so far. The difference between a 'GOOD performance and a 'GREAT' one is not about physical training conditioning, it's all about your mental skills and how you work with your coach and Team members. All the research point, It show that the top factor contributing to a personal best or medal-winning performance were a strong coach-athlete relationship, and a high level of athlete self-awareness.

What is a High-Performance Athlete?

Beyond body morphology endurance, strength, and power are primary factors underlying athlete performance .Aerobic endurance is the ability to sustain an aerobic effort over time, such as distance running or cycling. Muscular strength is the ability of the muscle to generate force.

High-Performance Training for sports will guide you in these areas,

1. Optimize the effectiveness of cross-training

2. Translate strength into speed.

3. Increase aerobic capacity and generate aerobic power.

4. Maintain peak conditioning throughout the season. 
5. Minimize the interference effect.

6. Design energy-specific performance programs.

\section{HIGH-PERFORMANCE TRAINING FOR ATHLETES}

A high-performance training program is designed to refine the skills and performance of individual participating at a high level. The main aim is to develop and enhance the physical capability of athletes.

Why it's important for a athlete transiting into a competition to know his or her body type.

Humans typically fall into one or three body type, ectomorph, mesomorph and endomorph.

\section{A. Ectomorph}

Characteristics;

$>$ Small frame and bone structure

$>$ Thin

$>$ Long and stringy muscles

$>$ Flat chest

$>$ Thin shoulders with little width

$>$ Difficult to gain weight

$>$ Fast metabolism

\section{B. Mesomorph}

Characteristics;

$>$ Naturally muscular

$>$ Athletic

$>$ Strong

$>$ Well-defined muscles

$>$ Rectangular-shaped physique

$>$ Easy to gain muscle

$>$ Easier to gain body fat than ectomorphs

\section{Endomorph}

Characteristics;

$>$ Soft round body

$>$ Shorter "stocky" build

$>$ Round physique

$>$ Thick arms and legs

$>$ Difficult to lose body fat

$>$ Slow metabolism

\section{PLANNING YOUR MEAL}

Everything you eat causes metabolic and physiological responses in your body. Each of the three macronutrients-Protein, Carbohydrate, and Fat plays in role in altering the shape and size of physique. Meal frequency is an important part of planning. How often you should eat a meal based on your body type. Here's a general guideline for how often you should eat a meal based on body type.

Ectomorph; every 2-3 hours

Mesomorph; every 2.5-3.5 hours

Endomorph; every 3.5-5 hours

The 4 main types of training are aerobic, anaerobic, flexibility and strength training

$>$ Aerobic training include continuous activities, such as running, swimming, circuit training and long-interval training. Aerobic training involve training the large muscle groups.(e.g. leg)to efficiently combine with the cardio respiratory system to supply a higher volume of oxygen to working muscles and therefore improve performance.

The (3) Rules of cardio equipment are as follow;

1. Warm up for (5) minutes beforehand.

2. Give every machine a 2-week test drive.

3. Switch machines every 3 to 4 weeks.

Anaerobic training involves high-intensity, short duration exercise(such as interval training).This method is characterized by repeated bursts over short distances at high intensity and are design to improve the two anaerobic energy pathways.

Flexibility training can be used to increase the range of motion of the joint and reduced the an injury and muscle soreness.

Strength training is used for many conditions. Resistance training is to increase the amount of force a muscle and increase the size of skeletal muscle. The workout in this section have been designed with four specific results in mind; losing fat, building muscle, getting stronger, and improving overall fitness. These are complete programs that have been designed to get you where you want to go in the quickest, most efficient way possible.

For High-Performance athletes includes,

$>$ Dietary assessment

$>$ Nutrition Planning

$>$ Menu Planning

$>$ Supplement advice

$>$ Sports physician

$>$ Physiotherapists

$>$ Masseurs

$>$ Chiropractors

High quality training is imperative to ensure athletes 
are prepared for high performance result. 3 Leading Factor for Top Performances are as follows:

1. Strong Coach-Athlete Relationship.

2. Athlete Self-Awareness.

3. Optimal Training Environment.

Coaches and athletes must be at one with their purpose goal in the high performance program and follow through to achieve the athletes Goals.

Sport development is a process whereby effective opportunities, processes, system and structures are set up to enable and encourage people in all or particular groups and areas to take part in sport for recreation or to improve their performance to whatever level they desire.(Collins 1995)

1. Participation Level

2. Performance Level

3. Excellence Level

\section{Participation Level}

Sport is now a habit, Embedded in lifestyle for some time at least (ideal; lifelong), Social dimension often important club.

\section{Performance Level}

Skilled play at a good club level, Competitive

\section{III.Excellence Level}

The peak of the pyramid, Elite sport at a high level (Country, National and International Competition)

There are mainly two factors contributing to lack of confidence for athletes,

A. Subjective Uncertainly

B. Uncontrollability

To improve confidence, Athletes should be educated to pay attention to those controllable factors such as warming up and ignore those uncontrollable factors such as referee.

The ultimate goal and intermediate goal of an athlete's training is essential for planning the training. the main source of relevant information about the goals of training is competition. the demands of competition together with an individual's predispositions(e.g. health, level of abilities, talent) determine the methods of training. the training plan must be effective, simple, and controllable, in case of minor changes in its goal.

The quality of competition depends on the level of skills and abilities of athletes and external conditions. Knowing the importance of particular skills, physical abilities, mental characteristics.

The style of sportsmen champion are physical and mental components different abilities and characteristics in different proportions. The style of sportsmen in any sports includes the age when the best results are most likely to be achieved. To make plan for the goal training for effectiveness for the main competition as follows,

A. Main tasks facing the athletes in the coming year. The athletes' long -term development as well as preparation for the year's main competition.

B. Schedule for the main competitions and for competition athletes must quality for them.

C. The minimal skill level and abilities need in competition.

D. Quantity, means, and methods of work that are dedicated to develop each skill and ability.

E. Goal of training tasks to ensure the effectiveness of preparation for the main competition.

F. To get the information, use for the training process.(what, how, when to test)

G. The choice of criteria, tests, and methods of control must relate to the goal and needs of particular stages of the training process.

\section{METHOD}

6-Key Element Selection Criteria, we should be doing,

1. =To select athletes with High standard Body structure in order to get Highly Qualified Athletes.

2. To select Outstanding Athletes during two or three years to get top performance As Aged- limited sport discipline. (e.g. Football, Athletes........)

3. To choose outstanding and Brilliant Athletes As Genetic.

4. To select Qualified Athletes and Train well As Aged-Unlimited sport discipline.

5. To select Athletes Undaunted - Spirit and Zeal and Perseverance.

6. To find out talented young and good mental new generation Athletes.

3-Key Element, we should be doing, To improve High-performance Athletes,

A. To choose effectively and systematically young and new Generation Athletes.

B. To train young Generation with advanced Technique with skilled coach and with intensive training. 
C. To Outstanding and Brilliant Athletes to ensure in order to achievement sport activities.

To make plans for a year, the following factors have to be considered,

Short- Term plan, we should be doing,

1. Local Competition to be competes.

2. Invitation Competition to be held.

3. Invitation Scientific Qualified Coach from aboard to be train.

4. To get Latest Techniques and Tactic to be conduct refresher Course for Coaches.

5. Joint-Training for Elite-Athlete and New young Generation.

Long-Term plan, we should be doing,

A. International-Skill-Recognition Certificate Coach to be appointed.

B. Conduction Local Training Courses with Scientific qualified Coaches.

C. Sending sport related coaches, Referees and sports official to aboard to attend international courses and seminar and meetings.

D. Evaluation teaching methodology and training methodology and sport selection criteria and Administration and Teaching Aids in every years.

\section{RESULTS}

In this respect, it is advisable to suggest all of you that one of the essential requirements for high performance athletes is to benefit greatly with training in autogenic breathing, visualization, and self-talk monitoring. These simple tactics help athletes reduced the stress response and allow them to perform at their best. To make the right choices as contest day nears, it will help to keep your goals and the methods you choose to achieve them in perspective.

\section{CONCLUSIONS}

The truth is, the science is saying exactly that Success is probably due to hundreds of different factors, all the interacting with one another. But the end result is that if you take5oooM marathon athletes in Hot season country, and 5000M marathon athletes in the Cold season country,(e.g. Training at altitude) and expose them to the same training, you will not see anything like the same success rate. That is due to genetic differences that are too complex to discover with the approach that has been adopted now. That genetic is vital, both in determining innate ability, and our response to training, and even our motivation or desire to exercise and train in the first place.

\section{REFERENCES}

1. Dan Lewindon, High Performance Training for sports, www.humalkinetics.com

2. High performance sport-WIKIpedia, htpp;//en.wikipedia.org'wiki>High---pe--

3. High performance training for athletes, syssm.com.au

4. THE SCIENCE OF SPORT, Talent training and performance; The secrets of success//Genes vs training

5. Dr. Leigh Robinson, Creating Excellent National Sport Organizations, OCA Sport Congress, Book of Research

6. Mohammad Ehsani, Ph.D. Tarbiat Modares University, Tehran, Iran, mensaniteh@yahoo.com, OCA Sport Congress, Book of Research

7. Seyed Reza Rahimi Moghaddam, Manager-Talent Identification, Canadian Sport Centre Ontario, Canada,smoghadda@cscontano.ca

8. Li-wei ZHANG, ph.D, Ed.D, Beijing Sport University, liweizhang@ @otmail.com(poster)

9. Science of Sports Training by Thomas Kurz http;//www.stadion.com 